Article

\title{
Long-Term Oral Treatment with Non-Hypoglycemic Dose of Glibenclamide Reduces Diabetic Retinopathy Damage in the Goto-KakizakiRat Model
}

\author{
Marianne Berdugo ${ }^{1}$, Kimberley Delaunay ${ }^{1}$, Cécile Lebon ${ }^{1}$, Marie-Christine Naud ${ }^{1}$, Lolita Radet ${ }^{1}$, Léa Zennaro ${ }^{1}$, \\ Emilie Picard 1, Alejandra Daruich 1,2, Jacques Beltrand 3,4,5, Elsa Kermorvant-Duchemin 1,6 , Michel Polak 3,4,5,7, \\ Patricia Crisanti ${ }^{1}$ and Francine F. Behar-Cohen ${ }^{1,8, * \text { (D) }}$
}

1 Physiopathology of Ocular Diseases: Therapeutic Innovations, Sorbonne University and Universityof Paris, Inserm UMRS 1138, F-75006 Paris, France; marianne.berdugo@gmail.com (M.B.);

kimberley.delaunay@live.fr (K.D.); cecile.lebon@sorbonne-universite.fr (C.L.); marie-christine.naud@crc.jussieu.fr (M.-C.N.); lolitaradet@gmail.com (L.R.); lea.zennaro@inovarion.com (L.Z.); emilie.picard@crc.jussieu.fr (E.P.); adaruich.matet@gmail.com (A.D.); elsa.kermorvant@aphp.fr (E.K.-D.); patricia.lassiaz@crc.jussieu.fr (P.C.)

2 Department of Ophthalmology, AP-HP Hospital University Necker-Sick Children, F-75015 Paris, France

3 Department of Paediatric Endocrinology, Gynecology and Diabetology, AP-HP Hospital University Necker-Sick Children, F-75015 Paris, France; jacques.beltrand@aphp.fr (J.B.); michel.polak@aphp.fr (M.P.)

check for updates

Citation: Berdugo, M.; Delaunay, K.; Lebon, C.; Naud, M.-C.; Radet, L.; Zennaro, L.; Picard, E.; Daruich, A.; Beltrand, J.; Kermorvant-Duchemin, E.; et al. Long-Term Oral Treatment with Non-Hypoglycemic Dose of Glibenclamide Reduces Diabetic Retinopathy Damage in the Goto-KakizakiRat Model. Pharmaceutics 2021, 13, 1095. https://doi.org/10.3390/ pharmaceutics13071095

Academic Editor: Monica M. Jablonski

Received: 31 May 2021

Accepted: 15 July 2021

Published: 17 July 2021

Publisher's Note: MDPI stays neutral with regard to jurisdictional claims in published maps and institutional affiliations.

Copyright: (c) 2021 by the authors. Licensee MDPI, Basel, Switzerland. This article is an open access article distributed under the terms and conditions of the Creative Commons Attribution (CC BY) license (https:/ / creativecommons.org/licenses/by/ $4.0 /)$.
4 Faculté de Santé, University of Paris, F-75006 Paris, France

5 Institut Cochin, InsermU1016, F-75005 Paris, France

6 Neonatal and Intensive Care Unit, AP-HP Hospital University Necker-Sick Children, F-75015 Paris, France

7 Institute Imagine, InsermU1163, F-75015 Paris, France

8 Ophthalmology, AP-HP Hospital Cochin, F-75005 Paris, France

* Correspondence: francine.behar@gmail.com

\begin{abstract}
Diabetic retinopathy (DR) remains a major cause of vision loss, due to macular edema, retinal ischemia and death of retinal neurons. We previously demonstrated that acute administration of glibenclamide into the vitreous, or given orally at a non-hypoglycemic dose, protected the structure and the function of the retina in three animal models that each mimic aspects of diabetic retinopathy in humans. In this pilot study, we investigated whether one year of chronic oral glibenclamide, in a non-hypoglycemic regimen (Amglidia ${ }^{\circledR}, 0.4 \mathrm{mg} / \mathrm{kg}$, Ammtek/Nordic Pharma, $5 \mathrm{~d} /$ week), could alleviate the retinopathy that develops in the Goto-Kakizaki (GK) rat. In vivo, retinal function was assessed by electroretinography (ERG), retinal thickness by optical coherence tomography (OCT) and retinal perfusion by fluorescein and indocyanin green angiographies. The integrity of the retinal pigment epithelium (RPE) that constitutes the outer retinal barrier was evaluated by quantitative analysis of the RPE morphology on flat-mounted fundus ex vivo. Oral glibenclamide did not significantly reduce the $\mathrm{Hb} 1 \mathrm{Ac}$ levels but still improved retinal function, as witnessed by the reduction in scotopic implicit times, limited diabetes-induced neuroretinal thickening and the extension of ischemic areas, and it improved the capillary coverage. These results indicate that low doses of oral glibenclamide could still be beneficial for the prevention of type 2 diabetic retinopathy. Whether the retinas ofpatients treated specifically with glibenclamideare less at risk of developing diabetic complications remains to be demonstrated.
\end{abstract}

Keywords: diabetic retinopathy; retinal neuroprotection; glibenclamide; glyburide; sulfonylureas; diabetes complications; retinal edema

\section{Introduction}

Diabetic retinopathy remains a major cause of vision loss in the working-age population of Western countries, andthe incidence may increase due to the increased prevalence of diabetes worldwide [1]. Indeed, despite the widespread use of intraocular anti-VEGF 
drugs and glucocorticoids, mainly designed to act on macular edema, visual function is threatened by ischemic insults and by direct diabetic-induced neuropathy [2,3]. The neuropathy occurs early, even before microangiopathy is detected, as shown by recent retinal imaging technologies [3] or by electrophysiology showing progressive deterioration of electrical retinal responses with loss of electrical signal amplitudes and extended response times, reflecting retinal neuron alterations $[4,5]$. This could explain the fact that despite long-term repeated intraocular injections of anti-VEGF and glucocorticoids, visual gain remains limited, of around five letters in real world studies [6,7]. To date, there is no available treatment to stop or even slow down retinal neurodegeneration.

Sulfonylureas, through binding to the sulfonylurea receptor (SUR), which is a subunit of SUR1-Kir6.2 and SUR1-TRPM4(NCCa-ATP) channels, not only provoke insulin secretion by the pancreas [8], but also exert neuroprotective effects through binding to SUR1 expressed in neurons, astrocytes, oligodendrocytes, endothelial cells and reactive microglia [9-13]. In cerebral ischemia, glibenclamide reduced brain edema, was neuroprotectant [14], and decreased the risk of haemorrhagic transformation after severe ischemia [13]. Recently, in a model oftemporary middle cerebral artery occlusion, low doses of oral glimepiride improved neurological functions, reduced infarct volume and brain edema, restored tight junction protein expression and suppressed inflammatory cytokines [15]. Large meta analysis have recapitulated results on the protective effect of oral sulfonylurea drugs and tried to define their therapeutic potential in stroke [16]. In the context of diabetes, children presenting a potassium channel mutation responsible for diabetes showed improved neuropsychological development after they were treated specifically with glibenclamide (glyburide) $[17,18]$. In patients with type 2 diabetes, large meta analysis showed that sulfonylureas, similarly to metformin, but unlike insulin therapy, improved the cognitive dysfunction [19].

In the field of ophthalmology, Nicholson et al. showed that although glibenclamide did not protect the optic nerve's proximal microvasculaturein a rodent model of anterior ischemic optic neuropathy, it reduced the optic nerve head edema [20]. We recently showedthat local delivery of glibenclamide protected against excitotoxic stress in vivo and improved the function and the structure of the diabetic retina in a type 2 diabetic rat model [21]. Indeed, the direct intraocular injection of glibenclamide in a model of excitotoxic retinal cell death increased a and b-wave ERG amplitudes and, in the Goto-Kakizaki diabetic rat, it reduced the b-wave ERG implicit times, demonstrating its ability to improve retinal function. In a neonate rat model of hyperglycemia-induced retinal degeneration, glibenclamide prevented ganglion cells loss. In addition, we showed that SUR1-TRPM4 and SUR1-Kir 6.2 co-localized in the primate macula that is enriched in cone photoreceptors, showing a potential direct effect of glibenclamide on photoreceptors [21]. This observation is supported by a recent study showing that glibenclamide regulates photoreceptor metabolism and inhibits the production of oxygen reactive species induced by the exposure of the photoreceptor's outer segment to light [22]. Altogether, these results indicate that sulfonylureas could exert direct neuroprotective effects on the diabetes-induced retinal neurodegeneration. To answer this question, we treated type 2 diabetic Goto-Kakizaki (GK) rats orally with a non-hypoglycemic dose of glibenclamide for 10 months and evaluated its effect on retinal function and diabetic retinopathy signs.

In summary, diabetic retinopathy remains one of the major causes of visual loss due to macular edema, ischemia and neuronal cell loss. Sulfonylureas, through binding to their receptor SUR1, show neuroprotective effects in the central nervous system as well as in rodent models of excitotoxicity and hyperglycemia-induced retinal degeneration. Short-term treatment with glibenclamide protected the ERG-assessed retinal function and reduces retinal cell death [21]. Moreover, SUR1 is expressed in the macula, particularly in cones that are responsible for visual acuity and colour vision, suggesting that glibenclamide might protect the diabetic retina in humans. In the present study, we used in vivo methods to evaluate whether long-term oral treatment with glibenclamide at a non-hypoglycemic dose could preserve the function and the morphology of GK rats' retinas. 


\section{Material and Methods}

\subsection{Animals and Animal Model; Ethical Concerns}

The Goto-Kakizaki rat is a non-obese and non-insulin-dependent type 2 diabetes mellitus model. It was raised in our animal facility from Taconic's genitors (Silkeborg, Denmark). $\mathrm{HbA} 1 \mathrm{c}$ was measured with $\mathrm{A} 1 \mathrm{C} \mathrm{NOW}+$ multitest system (Bayer, Leverkusen, Germany) at 2, 6 and 12 months. Diabetes was defined as a plasma glucose level $>250 \mathrm{mg} / \mathrm{dL}$ $(14 \mathrm{mmol} / \mathrm{L})$. In our colony, and as previously observed, only males developed hyperglycemia at approximately 8 weeks of age that stabilized around 14 weeks of age [23]. Metabolic dysfunction in the GK rat involves three pathogenic events with complex interactions: (1) three independent mutations in loci involved in insulin secretion, (2) gestational hyperglycemia responsible for a transgenerational decrease in the beta-cell mass, (3) loss of beta-cell differentiation due to chronic exposure to hyperglycemia [24]. Male GK rats develop late complications such as microangiopathy, nephropathy, neuropathy and retinopathy [25]. Although no animal model recapitulates all the features of human diabetic retinopathy, male GK rats develop progressive retinopathy with local inflammation, retinal circulatory abnormalities [26] and retinal edema [26-29], together with a thickening of the choroid [27], before microangiopathy develops at around 7 months [30], mimicking the kinetics of the events in human diabetic retina [31]. The retinopathy involves a PKCzetaoveractivation-linked blood-retinal barrier (BRB) breakdown, photoreceptor neurodegeneration [28,32], Müller cell swelling and morphological damage of the outer retina [21]. Our present study extended from 2 months up to 12 months of age, i.e.,from before high blood glucose onset until the advanced stage of retinopathy in male GK rats ( $n=10$ eyes in the glibenclamide-treated group; $n=18$ eyes in the vehicle-treated group). We used female euglycemic GK rats ( $n=10$ eyes) and Wistar rats ( $n=12$ eyes) as controls. Wistar rats were chosen as controls for ERG, since one study reported in 2019 that although no diabetes develops in female GK rats, some ERG abnormalities might occur [33].

All rats were kept in pathogen-free conditions with ad libitum food and water and were housed in a $12 \mathrm{~h}$ light/12 h dark cycle. They were weighed once a week. During the study, one rat died in the vehicle-treated and one in the glibenclamide-treated diabetic groups.

All experimental procedures were performed in accordance with the Association for Research in Vision and Ophthalmology (ARVO) statement for the use of animals in Ophthalmic and Vision Research as well as with the 2010/63/EU UE directive. Experimental procedures comply with the 3Rs and were approved by the local ethics committee: Charles Darwin European Council of the Université de Paris (authorization 03952.03, A75-580/A750612). All procedures were performed under general (ketamine $40 \mathrm{mg} / \mathrm{kg}$, Kétamine $100{ }^{\circledR}$, Virbac, France + xylasine $4 \mathrm{mg} / \mathrm{kg}$, Rompun $2 \%{ }^{\circledR}$, Bayer AG, Leverkusen, Germany) and local anesthesia (oxybuprocainchlorhydrate, Tetracaine ${ }^{\circledR}$ Théa Pharma, Clermont-Ferrand, France). Animals were sacrificed by intraperitoneal sodium pentobarbital $(150 \mathrm{mg} / \mathrm{kg})$ prior to enucleation.

\subsection{Long-Term Oral Glibenclamide Treatment}

Male GK rats were treated from 2 to 12 months with either oral pediatric glibenclamide suspension (Amglidia ${ }^{\circledR} 6 \mathrm{mg} / \mathrm{mL}, 0.2 \mathrm{mg} / \mathrm{kg}$ BID, Ammtek/Nordic Pharma, Paris, France-glibenclamide in hydroxyethylcellulose, lactic acid, purified water, sodium benzoate (E211), sodium citrate, xanthan gum) or with the vehicle. Non-diabetic control rats were treated by the same volume of vehicle. Oral gavage was performed twice a day (8:00 a.m. and 6:00 p.m.), 5 days a week. This drug regimen, not comparable to human treatment for diabetes, was chosen to induce minimal changes in the glycemic control. Since the half-life of glibenclamide is 8-10 h, drug levels are expected to be maintained after the drug is stopped and until it is eliminated (i.e., 2.3 days, covering the week end). 


\section{3. $q P C R-A B C C 8$ Neuroretinal Expression}

At 12 months, at the end of the treatment period, rats were sacrificed and neuroretinas from 5 vehicle-treated diabetic retinas and 3 glibenclamide-treated ones were isolated on ice and directly frozen until RNA isolation. Total RNA was extracted using the RNeasy mini kit (Qiagen, Courtaboeuf, France) according to the manufacturer's protocols. RNA concentration, purity and integrity were determined with a NanoPhotometer (Implen, München, Germany). First-strand cDNA was generated by reverse transcription using $0.5 \mu \mathrm{g}$ total RNA and the II Reverse TranscriptaseKit (Invitrogen, Waltham, MA, USA). Genomic DNA was removed on RNeasy columns before reverse transcription, according to the manufacturer's protocols. Expression of the ABCC8 gene, encoding the SUR1 receptor, and the GAPDH housekeeping gene was evaluated in a 96-well plate with Quantstudio 5 (Applied Biosystems by Thermofisher scientific, Waltham, MA, USA). Each $\mathrm{PCR}$ reaction was performed following manufacturer's instructions. The primers used are detailed in Table 1 . The threshold for calculating cycle threshold $\left(C_{t}\right)$ values was calculated automatically using QuantStudio 3 and 5 Real-Time PCR System Software.The relative expression of each gene was calculated using the 2- $\Delta \Delta \mathrm{Ct}$ method. $\mathrm{Ct}$ values were analyzed with the fold change and $p$ value of each gene (Student's $t$-test).

Table 1. Primers references.

\begin{tabular}{cccc}
\hline Gene & \multicolumn{3}{c}{ Primer Reference } \\
\hline ABCC8 & $\begin{array}{c}\text { TaqMan }{ }^{\mathrm{TM}} \text { Gene Expression Assay } \\
(\text { FAM) Rn01476317_m1 }\end{array}$ & $\# 4331182$ & Life Technologie SAS \\
GAPDH & $\begin{array}{c}\text { TaqMan }{ }^{\mathrm{TM}} \text { Gene Expression Assay } \\
(\text { FAM) Rn01775763_g1 }\end{array}$ & \#4331182 & Life Technologie SAS \\
\hline
\end{tabular}

\subsection{Electroretinography (ERG)—Visual Function Evaluation}

Bilateral full-field ERG responses were recorded at 12 months of age, following a 10-month-long treatment of either glibenclamide or vehicle oral suspension. Rats were anaesthetized by intramuscular ketamine $(80 \mathrm{mg} / \mathrm{kg}) /$ xylazine $(8 \mathrm{mg} / \mathrm{kg})$. The cornea was desensitized with a drop of $1 \%$ tetracainchlorhydrate (Tétracaine ${ }^{\circledR}$, Théa Pharma, Clermont-Ferrand, France), and mydriasis was obtained with drops of $0.5 \%$ tropicamid (Mydriaticum ${ }^{\circledR}$, Théa Pharma, Clermont-Ferrand, France). Eyelids were kept open by home-made latex "surgical drapes". Flash ERG recordings were performed with the GanzfeldVisioSystem device (Siem Bio-Médicale, Nîmes, France), adapted for rodents, sending light flashes. For scotopic electroretinograms, essentially representing rod-driven responses, rats were dark-adapted overnight. Flash intensities ranged from 0.0003 up to $10 \mathrm{~cd} . \mathrm{s} / \mathrm{m}^{2}$. For cone-driven responses, photopic electroretinograms were recorded following a $5 \mathrm{~min}$ light adaptation and a $10 \mathrm{~cd} . \mathrm{s} / \mathrm{m}^{2}$ flash intensity. In both conditions, 5 responses were averaged. Mixed responses refer to whole retinal responses (coming from both cone and rod-driven pathways). Negative a-wave amplitudes were measured from baseline to trough bottom. Positive b-wave amplitudes were measured from the bottom of the b-wave's trough to its peak. Implicit times of the first two oscillatory potentials were measured from time of stimulus to peaks. Results were expressed in microvolts $(\mu \mathrm{V})$ for amplitudes and milliseconds (ms) for implicit times (mean $\pm \mathrm{SD})(n=7$ to 16 eyes per group). Cursors were placed in a blind way. For details, see [21] Suppl Data.

\subsection{Fundoscopy, Optical Coherence Tomography (OCT)—Neuroretinal Thickness Measurement}

In vivo imaging of rat retinas was performed on anesthetized animals using the Micron III high resolution retinal imaging microscope (Phoenix Technology Group, Pleasanton, CA, USA) adapted for small animal eyes. Funduscopic examinations and Optical Coherence Tomography were performed at 12 months. OCT is a non-invasive imaging method that provides retina sections along chosen lines on fundus images. At least 5 OCT images were taken for each eye (one central and one temporal, nasal, inferior and superior quadrants of 
the retina), using the optic nerve head as a landmark. Neuroretinal thickness, measured with ImageJ software 3 times in a masked fashion, was compared in the same direction and same distance from the optic nerve.

\subsection{Fluorescein and Indocyanin Green Angiographies-Retinal and Choroidal Vascularization Imaging and Evaluation of Dye Vascular Infusion}

In vivo fluorescein and indocyanin green (ICG) angiographies were simultaneously performed to obtain images of both retinal and choroidal structures, in all 12-month-old rats. In this process, $150 \mu \mathrm{L}$ of a mixture made of fluorescein $\left(0.5 \%\right.$ Fluorescein ${ }^{\circledR}$ Faure for intravenous injections) and ICG (Infracyanin, $0.5 \mathrm{mg}$ in 5\% glucose; Serb) (50:50, v/v) wasinjected in the tail vein of anesthetized rats. Angiography pictures were taken with a confocal scanning laser ophthalmoscope (Spectralis Heidelberg Retinal Angiograph, HRA2, Heidelberg Engineering/Sanotek, Heidelberg, Germany) using a blue laser (488 nm, barrier filter at $500 \mathrm{~nm}$ ) and an infrared laser $(795 \mathrm{~nm}$, barrier filter at $800 \mathrm{~nm})$ for dye excitation. Bilateral images were collected at various time points.

Using a subjective scale and using all time points of angiography pictures, we scored the infusion of dyes within the retinal vessels in a blind fashion, as follows:

3-All vessels normally infused with fluorescein, no ischemic area

2-Some vessels are not well-infused, or few ischemic areas appear

1 -Most retinal vessels are not well-infused with fluorescein and/or ischemic areas are present

0 -Fluorescein infusion modified in the whole retina and/or many ischemic areas

We also counted the total number of ischemic areas per eye.

\subsection{Flatmounts, Immunohistochemistry and Home-Made Macro Analysis for Evaluation of Capillary Percentage among Retinal Vessels and RPE cell Areas Analysis}

After sacrifice, the eyes were enucleated, fixed for $1 \mathrm{~h}$ in $4 \%$ paraformaldehyde. They were dissected and the neuroretinas separated from RPE/choroid/sclera complex. Four radial cuts were made in each tissue for flat-mounting fixed $10 \mathrm{~min}$ at $-20{ }^{\circ} \mathrm{C}$ in acetone, blocked with fetal bovine serum $10 \%$ in PBS, $0.1 \%$ Triton for $30 \mathrm{~min}$. Retinas $(n=3$ to 6/group) were then incubated overnight at $4^{\circ} \mathrm{C}$ with TRITC-conjugated lectin (SigmaAldrich, St. Louis, MI, USA) at 1:300, 5 min in Dapi (4',6-diamidino-2-phénylindole) 1:5000 at RT, and flat-mounted with Fluoromount mounting medium (Sigma-Aldrich, St. Louis, MI, USA). RPE/choroid complexes ( $n=3$ to 6/group) were incubated with rhodamineconjugated anti-phalloidin antibody (Invitrogen, Waltham, MA, USA) 1:300 overnight at $4{ }^{\circ} \mathrm{C}$. Negative controls consisted of the omission of lectin or conjugated antibody. Six pictures per neuroretina at $\times 8$ magnification, and 20 pictures per RPE/choroid/sclera complex at $\times 40$ magnification, distributed all over the entire surface, were acquired with an Olympus microscope (BX51). Using these images and ImageJ software with a macro tool [29] developed on Fiji software, RPE images were used for morphological analysis, including RPE cell areas, as described in [29].

\subsection{Statistics}

Data are provided as mean \pm SD in non-diabetic, diabetic, and glibenclamide-treated diabetic groups at 6 or 12 months (i.e., at the termination of long-term treatment). Statistical analysis was performed using Graph Pad Prism 8. ANOVA followed by multiple comparison post-tests was used when more than two groups were compared (exact $p$ values are given), and theMann-Whitney-U test was used to compare two groups. $p<0.05$ was considered significant.

\section{Results}

3.1. Long-Term Oral Glibenclamide at $200 \mu \mathrm{g} / \mathrm{kg}$ BID did Not Influence Body Weight and Glycemic Control in GK Rats-qPCR ABCC8 Expression

Neither body weight nor glycated hemoglobin differed between the vehicle and glibenclamide-treated diabetic groups of male Goto-Kakizaki rats at 2, 6 and 12 months of 
age (Figure 1 and Table 2; two-way ANOVA and Bonferroni post-test; ${ }^{*} p<0.05,{ }^{* *} p<0.01$, $* * * p<0.001$ significant only for non-diabetic females vs. diabetic males GK rats). Quantitative PCR expression of ABCC 8 gene mRNA normalized with GAPDH mRNA tends to be increased by treatment in 12-month-old diabetic rat neuroretinas $(p=0.057)$.

(a)

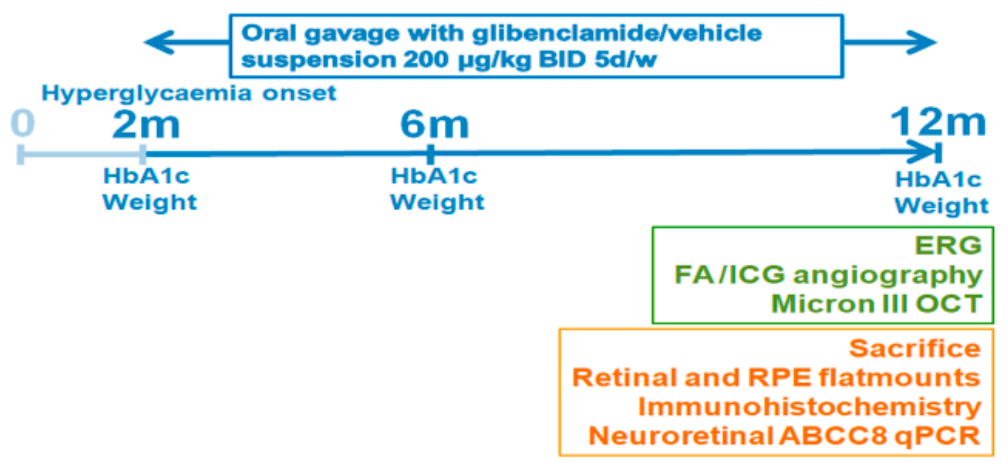

(b) Body weight

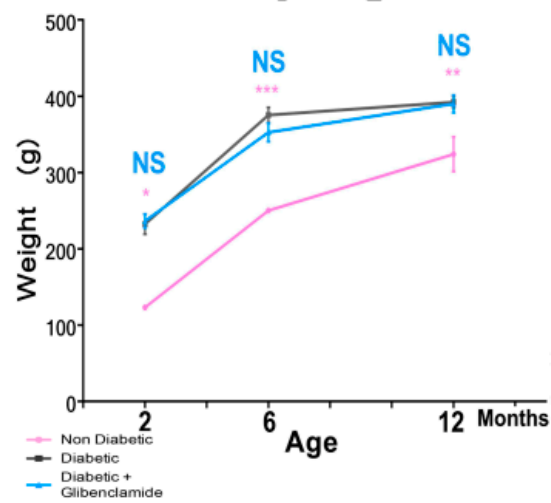

(c) Glycated hemoglobin

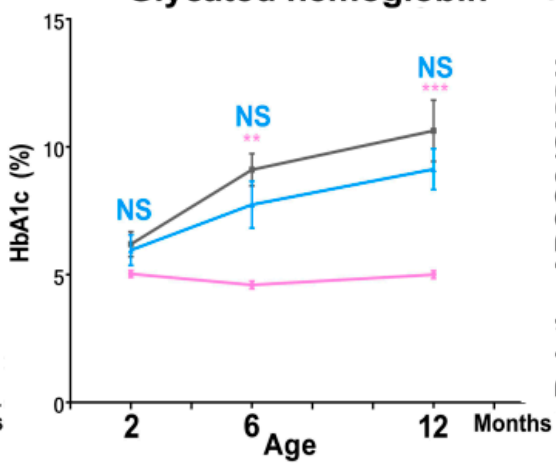

(d) Relative ABCC8 gene expression

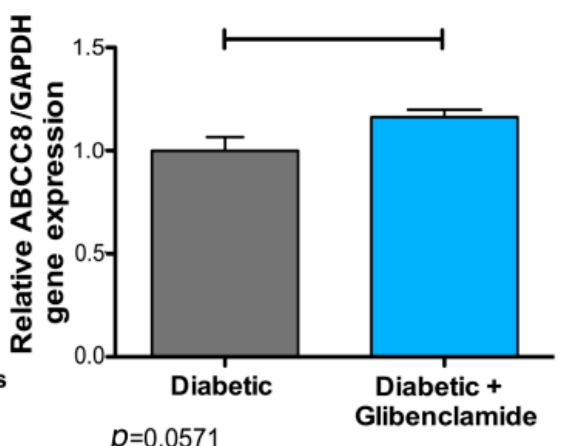

Figure 1. Schematic timeline schedule of the experiment, body weight, glycated hemoglobin, and relative ABCC8 (SUR1) qPCR expression. (a) Schematic timeline schedule of the experiment. (b) Body weight expressed as mean \pm SEM at 2, 6 and 12 months. ANOVA and Bonferroni's post-test vs. diabetic. ${ }^{*} p<0.05 ;{ }^{* *} p<0.01 ;{ }^{* * *} p<0.001(n=5,8$ and 5 rats, respectively, at 2 months, $n=3,8$ and 5 rats at 6 months, and $n=3,8$ and 4 rats at 12 months). Non-diabetic $=$ female GK rats; (c) glycated hemoglobin $(\mathrm{HbA} 1 \mathrm{c})$ in non-diabetic, diabetic and glibenclamide-treated diabetic animals, expressed as a mean percentage \pm SEM at 2, 6 and 12 months $(n=3,8$ and 5 rats, respectively, at 2 months, $n=3,8$ and 5 rats at 6 months, and $n=3,8$ and 4 rats at 12 months). ANOVA and Bonferroni's post-test vs. diabetic. ${ }^{* *} p<0.01 ;{ }^{* * *} p<0.001$; (d) Relative qPCR ABCC8 gene expression in neuroretinas at 12 months (after long-term low-dose oral glibenclamide treatment; $n=5$ and 3 rats, respectively, in diabetic and glibenclamide-treated diabetic animals). Mann-Whitney test $p=0.057$. Non-diabetic control $=$ pink, diabetic $=$ grey, long-term glibenclamide-treated diabetic $=$ blue .

Table 2. Mean $\mathrm{HbA1c}$ at 2, 6 and 12 months in non-diabetic female, diabetic male and glibenclamidetreated male GK rats.

\begin{tabular}{ccccccccccc}
\hline \multicolumn{3}{c}{ Non-Diabetic Females } & \multicolumn{3}{c}{ Diabetic } & \multicolumn{3}{c}{ Diabetic + GLI } \\
\hline $\begin{array}{c}\text { Age } \\
\text { (Months) }\end{array}$ & Mean & SD & $n$ & Mean & SD & $\boldsymbol{n}$ & Mean & SD & $\boldsymbol{n}$ \\
\hline 2 & 4.94 & 0.3 & 5 & 6.28 & 0.64 & 8 & 5.96 & 1.33 & 5 \\
6 & 4.6 & 0.27 & 3 & 9.15 & 0.65 & 8 & 7.74 & 2.05 & 5 \\
12 & 5 & 0.27 & 3 & 10.62 & 1.63 & 8 & 9.125 & 1.6 & 4 \\
\hline
\end{tabular}

3.2. Long-Term Non-Hypoglycemic Oral Glibenclamide Treatment Improves Retinal Function in GK Rats

At 12 months and after 10 months of oral treatment, ERG parameters that reflect the inner retinal activity were improved in male GK rats treated with glibenclamide as 
compared to untreated male GK, as shown by the significant reduction in implicit times (Figure 2). Indeed, the first and second scotopic oscillatory potential implicit times were, respectively $30.06 \pm 1.48$ and $40.7 \pm 2.18 \mathrm{~ms}$ in non-diabetic Wistar rats $(n=16), 33.5 \pm 1.09$ and $44.8 \pm 1.7 \mathrm{~ms}$ in vehicle-treated diabetic rats $(n=17)$ as compared to $32.1 \pm 0.4$ and $43.1 \pm 0.9 \mathrm{~ms}$ in glibenclamide-treated diabetic rats $(n=7)\left({ }^{* * *} p<0.0001,{ }^{*} p=0.02\right.$ and ${ }^{* * *} p=0.0009 ;{ }^{* * *} p<0.0001,{ }^{*} p=0.04$ and $\left.{ }^{* *} p=0.005\right)$. Mixed $a-$ and $b$-wave amplitudes were reduced by diabetes $(-18.6 \pm 4.47 \mu \mathrm{V}$ vs. $-8.67 \pm 5.37 \mu \mathrm{V}$ and $120.5 \pm 25.59 \mu \mathrm{V}$ vs. $112.3 \pm 15.67 \mu \mathrm{V})$, and not significantly protected by treatment $(-6.29 \pm 4.38 \mu \mathrm{V}$ and $93.7 \pm 17.8 \mu \mathrm{V} ;{ }^{* * * *} p<0.0001$ and ns). In photopic ERG conditions (not shown), the mixed blue flashes' a-wave implicit time that reflects the photoreceptors activity was significantly shorter in treated animals (mean implicit time $18.50 \pm 2.7 \mathrm{~ms}$ vs. $24.61 \pm 0.92 \mathrm{~ms}, p=0.024$ ). These results demonstrate improved electrical response times of the inner and the outer retina in diabetic GK rats treated by oral glibenclamide over a long period of time.

\subsection{Long-Term Non-Hypoglycemic Oral Glibenclamide Treatment Reduces Retinal Edema in GK Rats}

At the end of follow-up, OCT B-scans were taken in 12-month-old diabetic and glibenclamide-treated diabetic rats and in age-matched control rats (Figure 3). In male GK rats, the neuroretinal thickness was increased as compared to control rats (Figure 3c). Long-term oral glibenclamide partially prevented retinal thickening (Figure 3c), with a maximal effect observed in the temporal direction near the optic nerve (mean thicknesses were $349 \pm 3 \mu \mathrm{m}$ in non-diabetic animals, $414 \pm 11 \mu \mathrm{m}$ in diabetic rats and $367 \pm 11 \mu \mathrm{m}$ in glibenclamide-treated diabetic rats, two-way ANOVA $p<0.0001$, Bonferroni post-test $p<0.001$ vs. diabetic group). The thickness reduction was also significant at $2600 \mu \mathrm{m}$ from the optic nerve in both nasal and temporal directions (mean thicknesses were, respectively, $304 \pm 5$ and $311 \pm 3 \mu \mathrm{m}$ in non-diabetic animals, $344 \pm 2 \mu \mathrm{m}$ and $340 \pm 5 \mu \mathrm{m}$ in diabetic rats and $316 \pm 9 \mu \mathrm{m}$ and $314 \pm 7 \mu \mathrm{m}$ in glibenclamide-treated diabetic rats, Bonferronipost test $p<0.05$ vs. diabetic group). Note that the retinal thickness remains higher in glibenclamidetreated rats as compared to non-diabetic controls, without retinal thinning.

\subsection{Long-Term Non-Hypoglycemic Oral Glibenclamide Improves Retinal Vascular Perfusion in Diabetic Goto-Kakizaki Rats}

As shown in Figure 4e, vascular perfusion was significantly reduced in diabetic GK rats as compared to non-diabetic controls and glibenclamide significantly improved the perfusion angiographic score (ANOVA $p<0.0001$ and multiple comparison Dunn's posttest $p<0.001$ and $p<0.01 ; n=12,16$ and 9 , respectively). Non-perfused areas were also significantly reduced in glibenclamide-treated diabetic rats as compared to untreated diabetic controls (Kruskal-Wallis $p<0.01$ and Dunn's post-test, $p<0.01$ and $p<0.05 ; n=10$, 7 and 5, respectively) (Figure 4f). To further confirm the in vivoangiographic results, rats were sacrificed, and retinas were flat-mounted and labeled with TRITC-lectin (red), as shown in Figure $4 \mathrm{a}$ (and Figure $4 \mathrm{~b}$ at higher magnifications). Glibenclamide improved the retina coverage with small capillaries as compared to untreated diabetic rats (43.6 vs. $35.8 \%$ of small capillaries among vessels, $p=0.04)$. These converging results indicate that a lowdose of glibenclamide may reduce retinal microvascular abnormalities associated with chronic diabetes. 
(a)
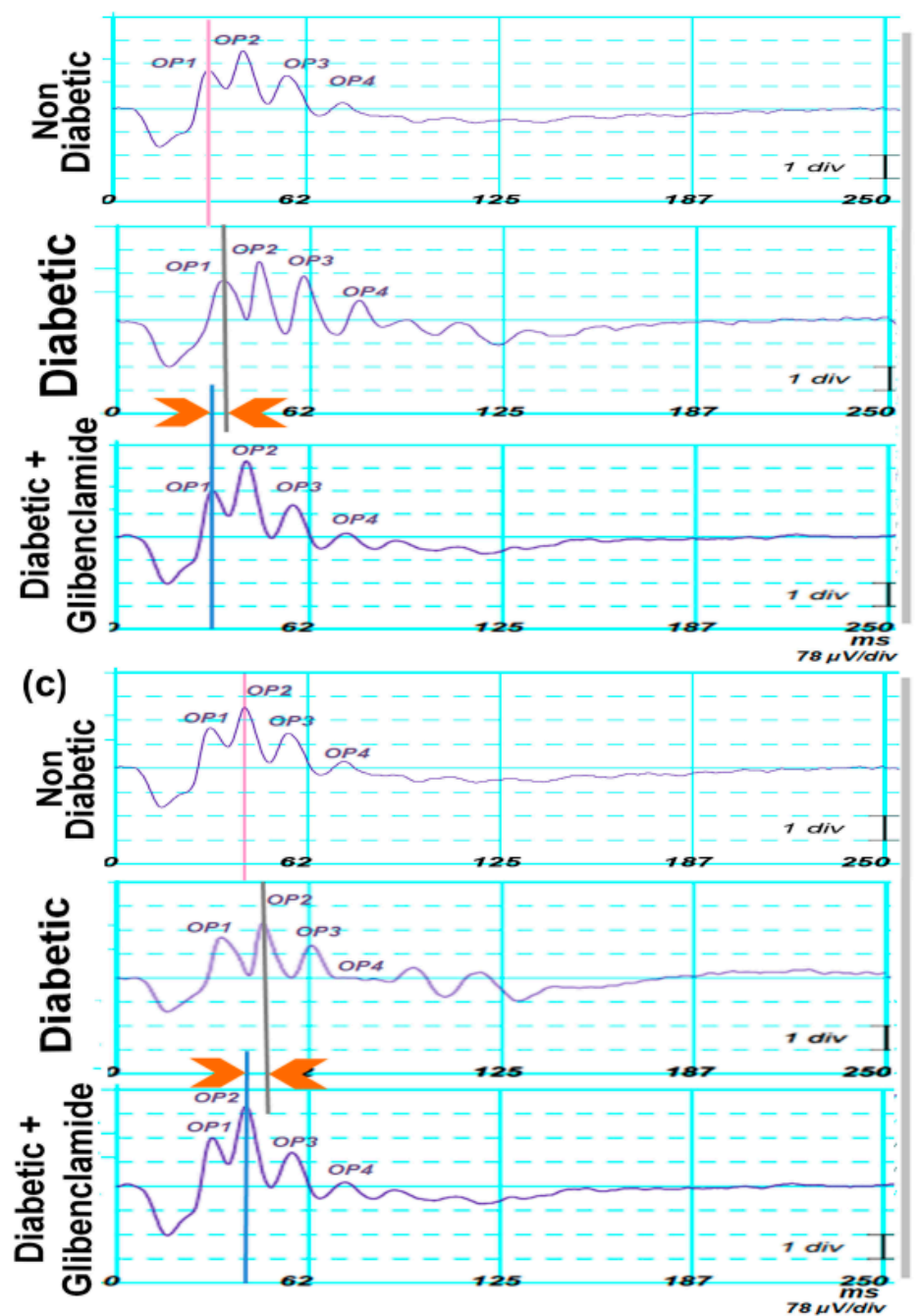

(e)

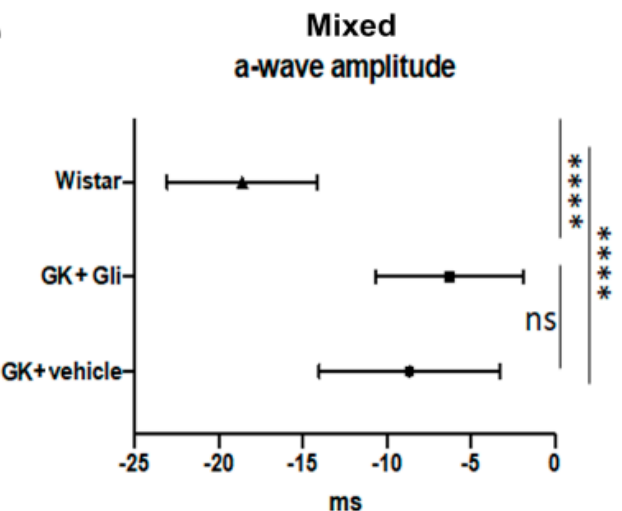

(b)

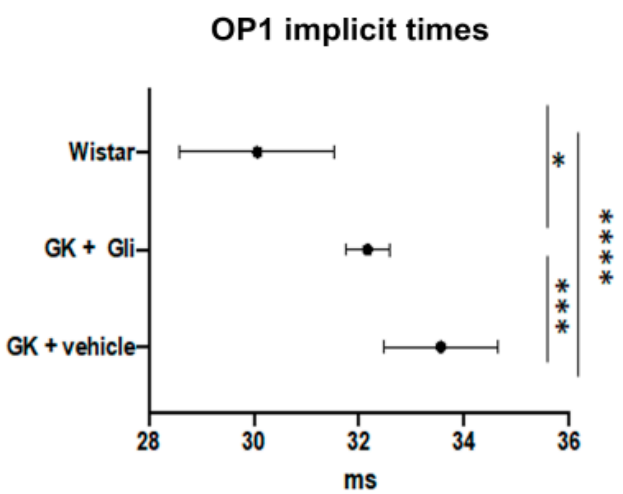

(d)

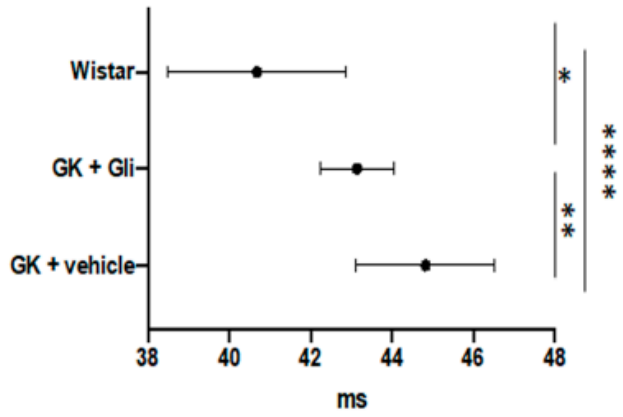

(f)

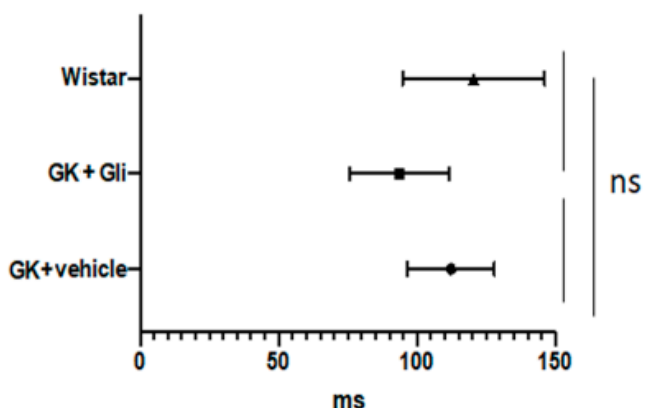

Figure 2. Long-term low-dose oral glibenclamide treatment improves retinal function through a reduction in ERG implicit times in diabetic Goto-Kakizaki rats. (a,c) Representative scotopic oscillatory potentials charts recorded in 12-month old non-diabetic Wistar rats ( $n=16$ eyes), vehicle-treated ( $n=17$ eyes) or glibenclamide-treated ( $n=7$ eyes) diabetic GK rats, showing an extension of implicit times with diabetes and a reduction with treatment; (b) OP1 (first oscillatory potential) $\left({ }^{*} p<0.05,{ }^{* * *} p<0.001,{ }^{* * * *} p<0.0001\right)$ and (d) OP2 corresponding implicit time graphs $\left({ }^{*} p<0.05,{ }^{* *} p<0.01,{ }^{* * * *} p<0.0001\right)$. (e) Mixed a-wave $\left.{ }^{* * * *} p<0.0001\right)$ and (f) mixed b-wave amplitude graphs in same groups. Mean \pm SD, ANOVA and multiple comparison post-test. 


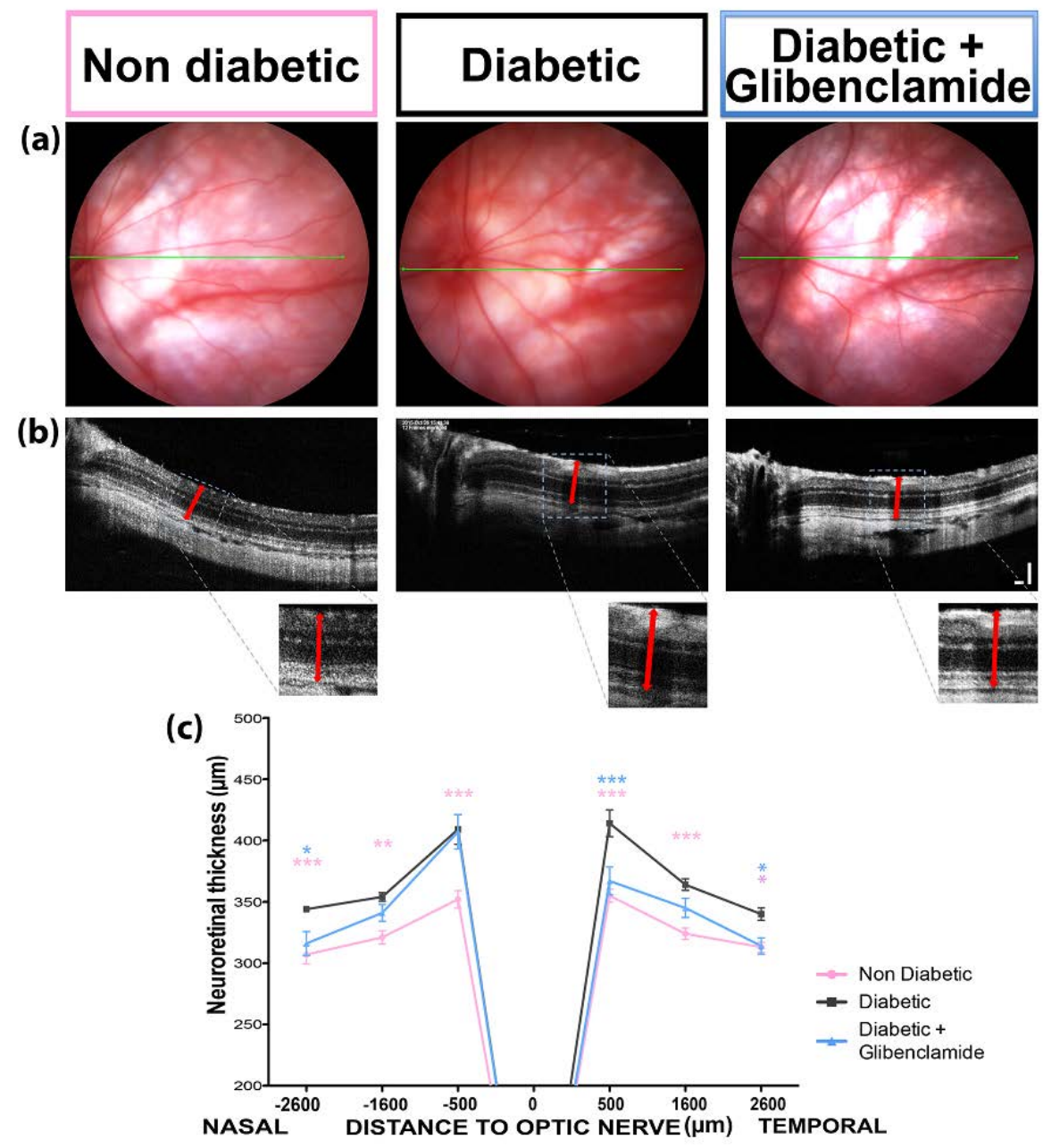

Figure 3. Long-term low-dose oral glibenclamide treatment reduces diabetes-induced retinal edema in diabetic Goto-Kakizaki rats. (a) Fundi pictures of 1-y-old non-diabetic female, diabetic and glibenclamide-treated diabetic rats obtained with Micron III device (Phoenix Research Labs); (b) corresponding Micron III OCT pictures used to measure neuroretina thickness at fixed distances from the optic nerve and known orientation (nasal-temporal); insert = thickness measurement; vertical scale bar $=200 \mu \mathrm{m}$, horizontal scale bar $=100 \mu \mathrm{m}$. (c) Neuroretinal thicknesses at 500, 1600 and $2600 \mu \mathrm{m}$ from the optic nerve, in nasal and temporal directions, in non-diabetic Wistar and female GK (pink line), diabetic (black line) and glibenclamide-treated diabetic (blue line) rats ( $n=6$ to 20 eyes). Two-way ANOVA and Bonferroni's post-test vs. diabetic group; ${ }^{*} p<0.05,{ }^{* *} p<0.01,{ }^{* * *} p<0.001$.

\subsection{Long-Term Non-Hypoglycemic Oral Glibenclamide Prevented Outer Retinal Barrier Damages}

On RPE/choroid flatmounts, RPE cells from male GK rats, stained with anti-phalloidin antibody (Figure 5a) exhibit increased cellular polydispersity and reduced cell size [29]. Indeed, in old diabetic rats, the mean RPE cellular area, smaller than in non-diabetic controls, was partially restored by glibenclamide (mean area $=93.2 \pm 0.6 \mu \mathrm{m}^{2}$ vs. $110.6 \pm 0.4 \mu \mathrm{m}^{2}$, Kruskal-Wallis test $p<0.0001$ and Dunn's multiple comparison test, $p<0.0001$ in nondiabetic vs. diabetic groups; $100.7 \pm 0.5 \mu \mathrm{m}^{2}$, Dunn's multiple comparison test, $p<0.0001$ in glibenclamide-treated vs. vehicle-treated diabetic groups). Glibenclamide also reduced RPE cells' polydispersity induced by diabetes (Figure 5). The effect of long term oral glibenclamide on RPE morphology changes indicates that glibenclamide could also prevent outer retinal barrier dysfunction. 


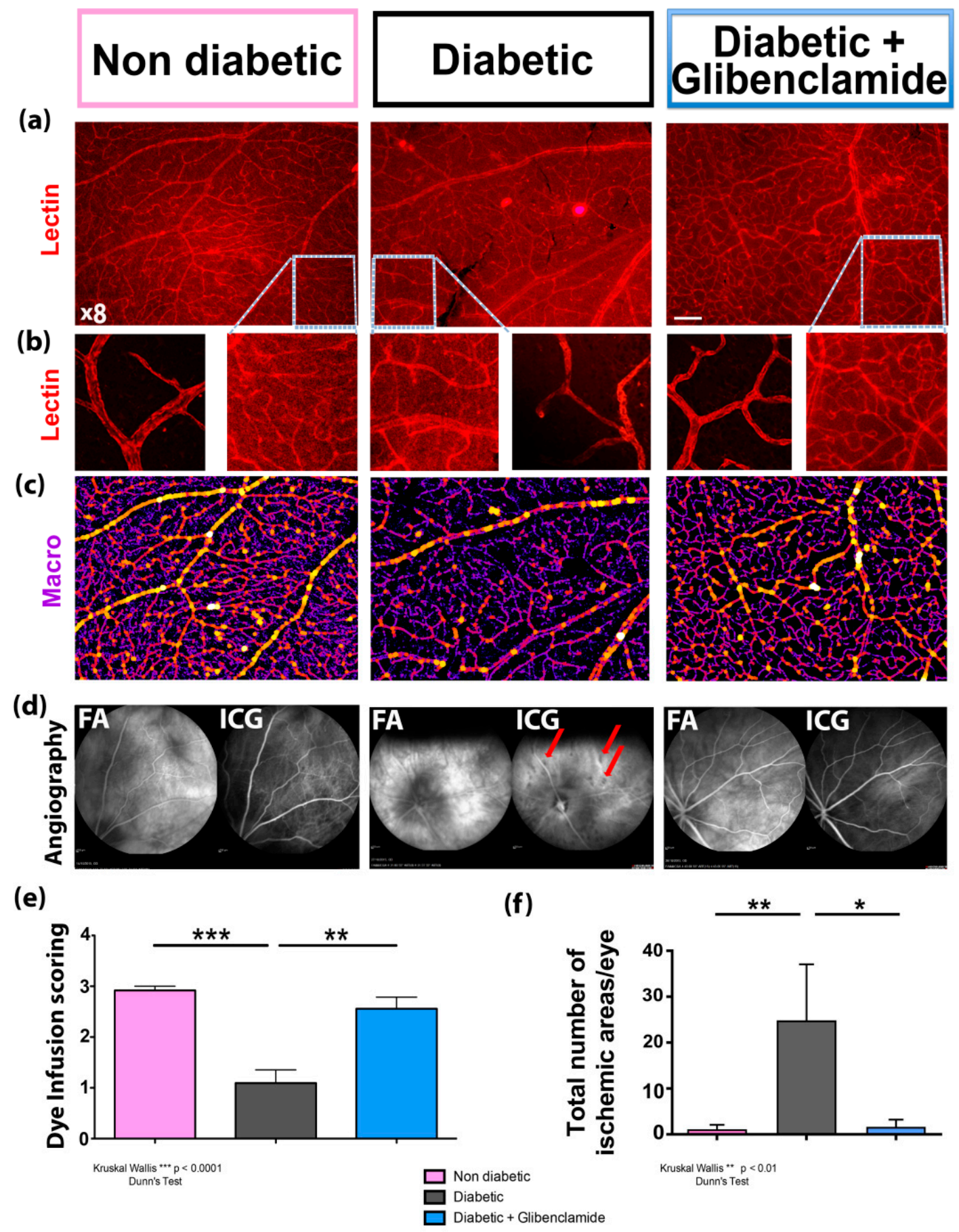

Figure 4. Glibenclamide improves retinochoroidal blood perfusion, and reduces the number of ischemic areas in diabetic Goto-Kakizaki rats. Non-diabetic female GK (left column) vs. diabetic male GK (middle column) vs. glibenclamide-treated diabetic GK (right column) rats. (a,b) Fluorescence microscope pictures of retinal flatmounts labeled with TRITC-lectin in 1-y old rats ( $\times 8$ in (a) Bar $=200 \mu \mathrm{m}$; higher magnification in (b)); (c) analyses of the previous pictures with a home-made macro in ImageJ software, which detects retinal vascular network and classifies vessels according to their diameters (small vessels in purple, medium vessels in red and large vessels in yellow); (d) in vivo confocal fluorescein (FA, left) and indocyanin green (ICG, right) angiographies at 4.30 min post dye intravenous injection in same groups; non-perfused ischemic spots (red arrows). (e) Subjective scoring of dye infusion in vessels at all time points (ANOVA $p<0.0001$ and multiple comparison Dunn's post-test ${ }^{* *} p<0.01$ and $\left.{ }^{* * *} p<0.001\right)$ in diabetic vs. non diabetic groups, and glibenclamide-treated vs. non-treated groups, $n=12,16$ and 9 eyes, respectively); (f) number of ischemic areas on angiographies in non-diabetic vs. diabetic vs. glibenclamide-treated diabetic groups ( $n=10,7$ and 5 eyes, respectively). Kruskal-Wallis $(p<0.01)$ and multiple comparison Dunn's post-test $\left.{ }^{*} p<0.05,{ }^{* *} p<0.01\right)$. Non-diabetic wistar + female GK rats = pink bar; diabetic GK rats = grey bar; glibenclamide-treated diabetic GK rats = blue bar. 


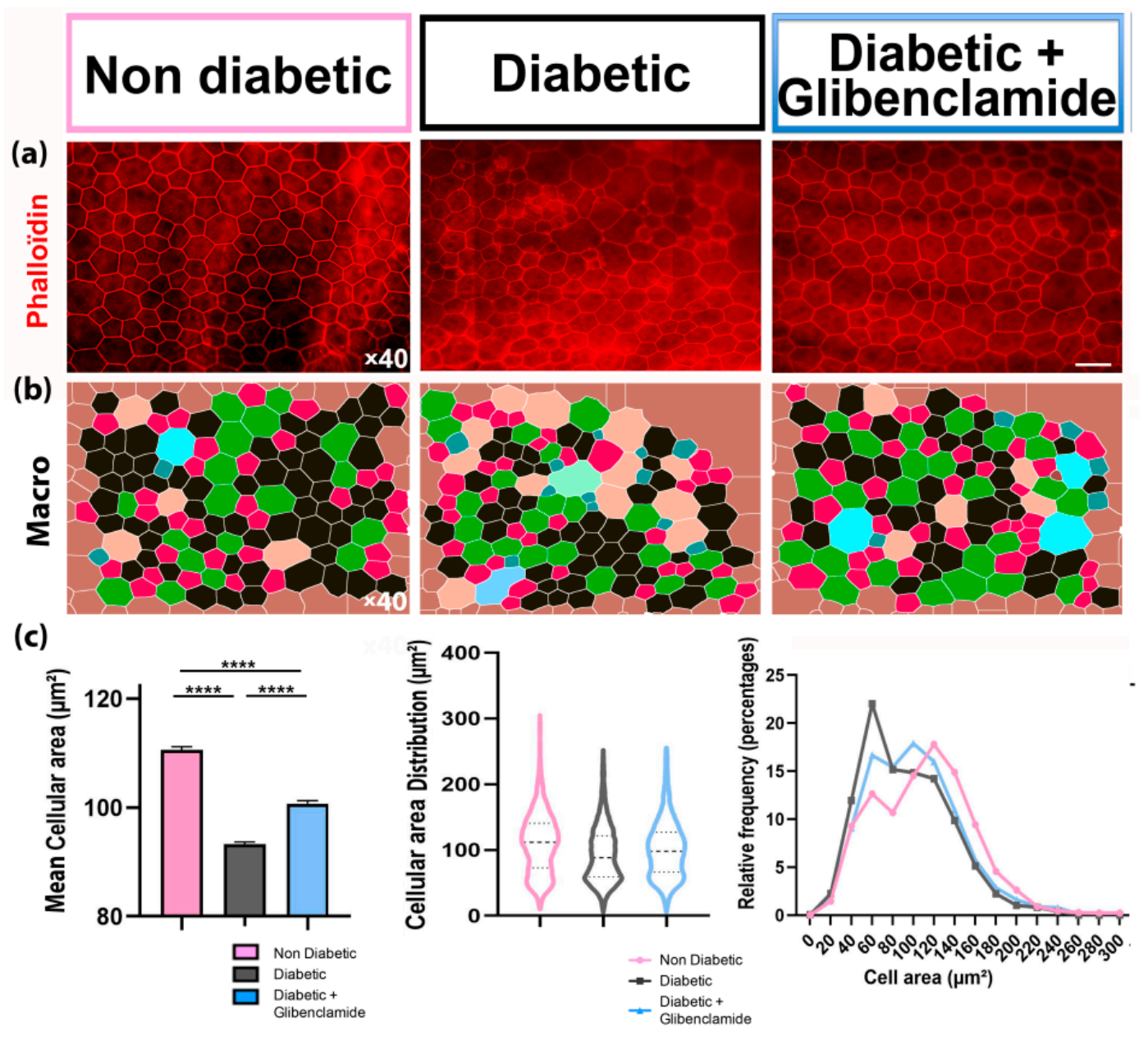

Figure 5. Long-term low-dose oral glibenclamide treatment protects RPE against diabetes-induced change in diabetic Goto-Kakizaki rats. (a) Retinal pigment epithelium flatmounts of 1-y-old non-diabetic female, diabetic and glibenclamidetreated diabetic rats; immunohistochemistry with anti-phalloïdin antibody and fluorescence microscope pictures $(\times 40)$; bar $=40 \mu \mathrm{m}$; (b) morphological analysis of those RPE pictures with a home-made macro in ImageJ software; (c) mean RPE cellular area $\left(\mu \mathrm{m}^{2}\right) \pm$ SEM (left; ANOVA $p<0.0001$ followed by Dunn's post-test $* * * * p<0.0001 ; n=5983,10,294$ and 6232 cells of 7, 4 and 4 eyes, respectively); distribution of cell areas (middle); relative frequency of cell areas (right) in each group: non diabetic control wistar + female GK rats = pink bar, violin and line; diabetic GK rats = grey bar, violin and line; glibenclamide-treated diabetic GK rats = blue bar, violin and line.

\section{Discussion}

We previously showed that short-term ocular administration of glibenclamide in the rat vitreous efficiently reduced retinal cell death in excitotoxic models and protected the retina of diabetic GK rats [21], confirming that glibenclamide is also neuroprotective in the retina. Interestingly, SUR1 and TRPM4 as well as Kir6.2 are expressed in glial retinal cells, ganglion cells, interneurons and in photoreceptors, particularly in primate photoreceptors in the macula, suggesting that glibenclamide can act directly on retinal cells and not only on the neurovascular unit. Recently, Ravera et al. used in vitro experiments to show that glibenclamide could interfere with the respiratory complex of rods by targeting the mitochondrial respiratory complexes I, II, and III and inhibiting the oxidative metabolism and oxidative stress. They also showed a synergistic effect of glibenclamide with metformin on reducing the production of oxygen reactive species [22]. 
Our study confirms that glibenclamide exerts beneficial effects on various signs of diabetic retinopathy in the GK rats, even when taken orally at a non-hypoglycemic dose for a long period of time.

On ERG, the scotopic oscillatory potentials resulting from the activity of the ONbipolar cells and the lateral inhibitory pathways of the inner retinal neurons [34] are delayed in diabetic vs. non-diabetic animals, as shown by the extension of their implicit times. Glibenclamide significantly reduced the implicit times of scotopic oscillatory potentials (that mostly measures rod pathway function). This is in line with our previous results showing that short-term glibenclamide treatment reduces scotopic b-wave implicit time delay in old GK rats [21]. Similarly, OPS delay was observed in rats with streptozotocin-induced diabetes [35,36] and in patients with type 2-diabetes with or without retinopathy [35]. In patients with diabetes, the OP1 implicit time delay is recognized as an early sign of visual dysfunction, whilst other OPS implicit time delays occur later [5]. On the other hand, an oral low dose of glibenclamide did not prevent the diabetes-induced a and b-wave amplitude reduction, suggesting that further studies remain to be conducted in other models of diabetes, to determine the optimized dose and route of glibenclamide administration to prevent efficiently retinopathy.

Retinal thickness, measured more specifically in the macula, is the main clinical parameter to detect and quantify edema and guide therapeutic indications in diabetic patients. Although no rodent model can recapitulate diabetic macular edema, similar pathogenic mechanisms have been described in GK rats and in humans [37], and in diabetic GK rats, retinal thickness is also increased but in a more diffuse manner. Using a long-term low dose of glibenclamide, retinal thickness was reduced, as observed with short-term local treatment [21], although the retina remained thicker than in non-diabetic Wistar rats and no thinning was observed. Depending on the model and the studied time points, various retinal morphological changes were reported in vivo using OCT. Whilst retina thinning was observed in 20-week-old db/+ mice [38], retina thickening was noted in 40 week-old diabetic Torii fatty and non-fatty rats [39], showing that in the long term, loss of visual neurons can be measured.

The anti-edematous effect of glibenclamide has been well documented in the brain under ischemic conditions [40] and a large multicentric randomized controlled study is currently evaluating the potential beneficial effects of glibenclamide for cerebral edema reduction after intracerebral hemorrhage [41]. In ischemic or traumatic brain cells, binding of glibenclamide to SUR1-TRPM4 reduces depolarization, which reduces blood-brain barrier breakdown and vasogenic edema [42]. In addition, in the retina, glibenclamide anti-edematous effects could result from the inhibition of the NOD-like receptor pyrin domain containing 3 (NLRP3) inflammasome and related neuroinflammation [43], known to be involved in diabetic retinopathy mechanisms [44-46]. In clinical studies, whether glibenclamide or other sulfonylurea drugs could improve the management of patients with diabetic macular edema has not been demonstrated, but the present result could prompt further studies on the subject.

Finally, a low dose of oral glibenclamide reduced the retinal microvasculature abnormalities detected in one-year-old male GK rats and protected RPE cells, which form the outer retinal barrier. These results show that glibenclamide, even at a very low dose, exerts beneficial effects on the different mechanisms causing vision loss in patients.

The exact dose that reaches the eye after oral administration of glibenclamide at $400 \mu \mathrm{g} / \mathrm{kg} / \mathrm{d}$ cannot be ascertained, although previous studies showed that efficient drug levels can be reached in the brain even at much lower doses (i.e., $4 \mu \mathrm{g} / \mathrm{kg} / \mathrm{d}$ ). In a previous study, we showed that one oral administration of $210 \mu \mathrm{g} / \mathrm{kg}$, which is a similar dose, of glibenclamide suspension (Amglidia ${ }^{\circledR}$, Ammtek/Nordic Pharma, France) in 9-week-old Wistar rats resulted in 0.26 and $0.3 \mathrm{ng} / \mathrm{mL}$ intraocular concentrations 1 and $2 \mathrm{~h}$ after intake, respectively, which were sufficient to achieve a neuroprotective effect locally [21]. In diabetic animals, we expect the intraocular biodisponibility to be higher, due to the 
breakdown of blood retinal barrier. It should be noted that the doses used to lower blood glucose in the GK rat (1 to $50 \mathrm{mg} / \mathrm{kg}$ ) are higher than in humans [47-50].

In clinical practice, diabetic patients are treated for years with doses of glibenclamide up to $15 \mathrm{mg} /$ day, and it is thus expected that neuroprotective doses will be reached in the retina, especially with regard to the barrier breakdown that occurs. Other common hypoglycemic drug classes have shown neuroprotective effects in the brain and in the retina, such as metformin, with potential synergistic effects with glibenclamide. On the other hand, insulinotherapy has been associated with reduced cognitive functions in patients with moderate type 2 diabetes [19].

A possible limitation of this study is a non-statistically significant trend toward a decrease in glycated hemoglobin in the glibenclamide-treated group, at $400 \mu \mathrm{g} / \mathrm{kg} / \mathrm{d}$ orally. However, in our previous experiments, glibenclamide was administered (1) orally, at the same dosing regimen, in streptozotocin-induced hyperglycemic rat pups, and (2) intravitreously in adult rats, and in both conditions, although it did not influence $\mathrm{HbA} 1 \mathrm{c}$, we did observe retinal neuroprotective effects [21]. Thus, although it cannot be excluded that a nonstatistically significant decrease in glycemia could influence the fate of diabetic retinopathy, it is unlikely since a strict control of the glycemia is required to limit retinopathy occurrence and severity in patients.

Our study also indicates that glibenclamide, particularly if formulated for ocular delivery, could be used for other degenerative retinal diseases associated with oxidative stress, inflammation and inflammasome activation, such as age-related macular degeneration (AMD). Recently, metformin was found to potentially reduce the incidence of AMD in large, retrospective studies [51] that need to be interpreted with caution [52]. Taking into account the fact that no treatment is currently available to prevent or delay retinal degeneration, the effects of old and known drugs with a known safety profile could be evaluated in treated patients that are affected by retinal diseases that induce rapid retinal cell death, such as retinal detachment [53].

\section{Conclusions}

This pilot study confirms our previous findings, indicating that the local intraocular delivery of glibenclamide was neuroprotective in several models of retinal damage. Further study is warranted to confirm these findings in other animal models and evaluate a correlation with human patients.

Author Contributions: Conceptualization: M.B., M.P., J.B., P.C. and F.F.B.-C.; Formal analysis: M.B., K.D., C.L., M.-C.N., L.R., L.Z., A.D., and P.C.; Funding acquisition: M.B., M.P. and F.F.B.-C.; Investigation: M.B., K.D., C.L., L.R. and P.C.; Methodology: M.B., K.D., C.L., E.P., J.B., E.K.-D., M.P., P.C. and F.F.B.-C.; Project administration: M.B., M.-C.N. and F.F.B.-C.; Resources: M.B., K.D., M.-C.N., A.D., E.K.-D., and F.F.B.-C.; Software, K.D. and C.L.; Supervision: M.B., M.P., P.C., A.D., E.K.-D. and F.F.B.-C.; Validation: M.B., P.C., A.D., E.K.-D., M.P. and F.F.B.-C.; Visualization: M.B., K.D., C.L., L.R., L.Z., F.F.B.-C. and P.C.; Writing-original draft: M.B. and F.F.B.-C.; Writing-review and editing: K.D., C.L., J.B., E.K.-D., M.-C.N., L.R., L.Z., A.D., E.P., M.P. and P.C. All authors have read and agreed to the published version of the manuscript.

Funding: This study was funded by the AgenceNationale de la Recherche (ANR-15-CE18-0032), the Fondation de France, the association Centre de RechercheenOphtalmologie (CRO)-Tous Unis pour la Vision (https: / /www.pourlavision.org; access on 31 May 2021), the Aide aux JeunesDiabétiques, and the Société Francophone du Diabète, which had no involvement in the study.

Institutional Review Board Statement: All experimental procedures were performed in accordance with the 2010/63/EU UE directive. Experimental procedures comply with the 3Rs and were approved by the local ethics committee: Charles Darwin European Council of the Universite de Paris (authorization 03952.03, A75-580/A750612).

Informed Consent Statement: No applicable.

Data Availability Statement: Upon request. 
Acknowledgments: This study contributes to the IdexUniversite de Paris ANR-18-IDEX-0001. The authors thank Simon Perreau, Georges Zadique (Sorbonne Université and Université de Paris, Inserm UMRS 1138, Centre de Recherche des Cordeliers, Centre d'ExplorationsFonctionnelles, F-75006 Paris, France), Emmanuelle Gélizé, Dalen Rosa, ThéoGuyon, Laurent Jonet, Jean-Claude Jeanny, Min Zhao, Alicia Torriglia, and Christophe Klein (Sorbonne Université and Université de Paris, Inserm UMRS 1138, Centre de Recherche des Cordeliers, CHICCentre for Histology, cellImaging and flowCytometry, F-75006 Paris, France) for their participation in experiments, analyses and setting up macros.

Conflicts of Interest: M.P. is scientific adviser for Ammtek. The funders had no role in the design of the study, in the collection, analyses, or interpretation of data, in the writing of the manuscript, or in the decision to publish the results.

\section{References}

1. Nentwich, M.M.; Ulbig, M.W. Diabetic Retinopathy-Ocular Complications of Diabetes Mellitus. World J. Diabetes 2015, 6, 489-499. [CrossRef] [PubMed]

2. Soni, D.; Sagar, P.; Takkar, B. Diabetic Retinal Neurodegeneration as a Form of Diabetic Retinopathy. Int. Ophthalmol. 2021. [CrossRef]

3. Damian, I.; Nicoară, S.D. Correlations between Retinal Arterial Morphometric Parameters and Neurodegeneration in Patients with Type 2 Diabetes Mellitus with No or Mild Diabetic Retinopathy. Medicina 2021, 57, 244. [CrossRef]

4. Li, Q.; Zemel, E.; Miller, B.; Perlman, I. Early Retinal Damage in Experimental Diabetes: Electroretinographical and Morphological Observations. Exp. Eye Res. 2002, 74, 615-625. [CrossRef]

5. Tzekov, R.; Arden, G.B. The Electroretinogram in Diabetic Retinopathy. Surv. Ophthalmol. 1999, 44, 53-60. [CrossRef]

6. Ciulla, T.A.; Pollack, J.S.; Williams, D.F. Visual Acuity Outcomes and Anti-VEGF Therapy Intensity in Diabetic Macular Oedema: A Real-World Analysis of 28658 Patient Eyes. Br. J. Ophthalmol. 2021, 105, 216-221. [CrossRef]

7. Rittiphairoj, T.; Mir, T.A.; Li, T.; Virgili, G. Intravitreal Steroids for Macular Edema in Diabetes. Cochrane Database Syst. Rev. 2020, 11, CD005656. [CrossRef]

8. Sharma, M.; Nazareth, I.; Petersen, I. Trends in Incidence, Prevalence and Prescribing in Type 2 Diabetes Mellitus between 2000 and 2013 in Primary Care: A Retrospective Cohort Study. BMJ Open 2016, 6, e010210. [CrossRef]

9. Kurland, D.B.; Gerzanich, V.; Karimy, J.K.; Woo, S.K.; Vennekens, R.; Freichel, M.; Nilius, B.; Bryan, J.; Simard, J.M. The Sur1-Trpm4 Channel Regulates NOS2 Transcription in TLR4-Activated Microglia. J. Neuroinflamm. 2016, 13, 130. [CrossRef]

10. Kunte, H.; Schmidt, S.; Eliasziw, M.; del Zoppo, G.J.; Simard, J.M.; Masuhr, F.; Weih, M.; Dirnagl, U. Sulfonylureas Improve Outcome in Patients with Type 2 Diabetes and Acute Ischemic Stroke. Stroke 2007, 38, 2526-2530. [CrossRef]

11. Sheth, K.N.; Simard, J.M.; Elm, J.; Kronenberg, G.; Kunte, H.; Kimberly, W.T. Human Data Supporting Glyburide in Ischemic Stroke. Acta Neurochir. Suppl. 2016, 121, 13-18. [CrossRef]

12. Jha, R.M.; Mondello, S.; Bramlett, H.M.; Dixon, C.E.; Shear, D.A.; Dietrich, W.D.; Wang, K.K.W.; Yang, Z.; Hayes, R.L.; Poloyac, S.M.; et al. Glibenclamide Treatment in Traumatic Brain Injury: Operation Brain Trauma Therapy. J. Neurotrauma 2021, 38, 628-645. [CrossRef]

13. Igarashi, T.; Sastre, C.; Wolcott, Z.; Kimberly, W.T. Continuous Glibenclamide Prevents Hemorrhagic Transformation in a Rodent Model of Severe Ischemia-Reperfusion. J. Stroke Cereb. Dis. 2021, 30, 105595. [CrossRef]

14. Caffes, N.; Kurland, D.B.; Gerzanich, V.; Simard, J.M. Glibenclamide for the Treatment of Ischemic and Hemorrhagic Stroke. Int. J. Mol. Sci. 2015, 16, 4973-4984. [CrossRef] [PubMed]

15. Wang, X.; Chang, Y.; He, Y.; Lyu, C.; Li, H.; Zhu, J.; Liu, K.; Hu, Y.; Huang, K.; Pan, S. Glimepiride and Glibenclamide Have Comparable Efficacy in Treating Acute Ischemic Stroke in Mice. Neuropharmacology 2020, 162, 107845. [CrossRef]

16. Wen, L.; Huang, B.; Tu, R.; Wan, K.; Zhang, H.; Zhang, X. Effectiveness and Safety of Glibenclamide for Stroke: Protocol for a Systematic Review and Meta-Analysis. BMJ Open 2021, 11, e043585. [CrossRef]

17. Beltrand, J.; Elie, C.; Busiah, K.; Fournier, E.; Boddaert, N.; Bahi-Buisson, N.; Vera, M.; Bui-Quoc, E.; Ingster-Moati, I.; Berdugo, M.; et al. Sulfonylurea therapy benefits neurological and psychomotor functions in patients with neonatal diabetes owing to potassium channel mutations. Diabetes Care 2015, 38, 2033-2041. [CrossRef] [PubMed]

18. Beltrand, J.; Busiah, K.; Vaivre-Douret, L.; Fauret, A.L.; Berdugo, M.; Cavé, H.; Polak, M. Neonatal Diabetes Mellitus. Front. Pediatr. 2020, 8, 540718, Published 30 September 2020. [CrossRef]

19. Zhang, Q.-Q.; Li, W.-S.; Liu, Z.; Zhang, H.-L.; Ba, Y.-G.; Zhang, R.-X. Metformin Therapy and Cognitive Dysfunction in Patients with Type 2 Diabetes: A Meta-Analysis and Systematic Review. Medicine (Baltim.) 2020, 99, e19378. [CrossRef] [PubMed]

20. Nicholson, J.D.; Guo, Y.; Bernstein, S.L. SUR1-Associated Mechanisms Are Not Involved in Ischemic Optic Neuropathy 1 Day Post-Injury. PLoS ONE 2016, 11, e0148855. [CrossRef]

21. Berdugo, M.; Delaunay, K.; Naud, M.-C.; Guegan, J.; Moulin, A.; Savoldelli, M.; Picard, E.; Radet, L.; Jonet, L.; Djerada, Z.; et al. The Antidiabetic Drug Glibenclamide Exerts Direct Retinal Neuroprotection. Transl. Res. 2020. [CrossRef]

22. Ravera, S.; Caicci, F.; Degan, P.; Maggi, D.; Manni, L.; Puddu, A.; Nicolò, M.; Traverso, C.E.; Panfoli, I. Inhibitory Action of Antidiabetic Drugs on the Free Radical Production by the Rod Outer Segment Ectopic Aerobic Metabolism. Antioxidants (Basel) 2020, 9, 1133. [CrossRef] 
23. Díaz, A.; López-Grueso, R.; Gambini, J.; Monleón, D.; Mas-Bargues, C.; Abdelaziz, K.M.; Viña, J.; Borrás, C. Sex Differences in Age-Associated Type 2 Diabetes in Rats-Role of Estrogens and Oxidative Stress. Oxidative Med. Cell. Longev. 2019, 6734836. [CrossRef] [PubMed]

24. Portha, B. Anomalies programmées de la sécrétion d'insuline dans le diabète de type 2: Le paradigme du rat GK [Transmitted beta-cell dysfunction as a cause for type 2-diabetes]. Med. Sci. (Paris) 2003, 19, 847-853. [CrossRef] [PubMed]

25. Kakizaki, M.; Masaki, N. Spontaneous diabetes produced by selective breeding of normal Wistar rats. Proc. Jpn. Acad. 1975, 51, 85-90.

26. Miyamoto, K.; Ogura, K.; Nishiwaki, H.; Matsuda, N.; Honda, Y.; Kato, S.; Ishida, H.; Seino, Y. Evaluation of retinal microcirculatory alterations in the Goto-Kakizaki rat. A spontaneous model of non-insulin-dependent diabetes. Investig. Ophthalmol. Vis. Sci. 1996, 37, 898-905.

27. Campos, A.; Martins, J.; Campos, E.J.; Silva, R.; Ambrósio, A.F. Choroidal and retinal structural, cellular and vascular changes in a rat model of Type 2 diabetes. Biomed. Pharmacother. Biomed. Pharmacother. 2020, 132, 110811. [CrossRef] [PubMed]

28. Omri, S.; Behar-Cohen, F.; Rothschild, P.R.; Gélizé, E.; Jonet, L.; Jeanny, J.C.; Omri, B.; Crisanti, P. PKCzeta mediates breakdown of outer blood-retinal barriers in diabetic retinopathy. PLOS ONE 2013, 8, e81600. [CrossRef]

29. Rothschild, P.R.; Salah, S.; Berdugo, M.; Gelize, E.; Delaunay, K.; Naud, M.C.; Klein, C.; Moulin, A.; Savoldelli, M.; Bergin, C.; et al. ROCK-1 Mediates Diabetes-Induced Retinal Pigment Epithelial and Endothelial Cell Blebbing: Contribution to Diabetic Retinopathy. Sci. Rep. 2017, 7, 8834. [CrossRef] [PubMed]

30. Hachana, S.; Pouliot, M.; Couture, R.; Vaucher, E. Diabetes-Induced Inflammation and Vascular Alterations in the Goto-Kakizaki Rat Retina. Curr. Eye Res. 2020. [CrossRef]

31. Wang, W.; Liu, S.; Qiu, Z.; He, M.; Wang, L.; Li, Y.; Huang, W. Choroidal Thickness in Diabetes and Diabetic Retinopathy: A Swept Source OCT Study. Investig. Ophthalmol. Vis. Sci. 2020, 61, 29. [CrossRef] [PubMed]

32. Omri, S.; Behar-Cohen, F.; de Kozak, Y.; Sennlaub, F.; Verissimo, M.L.; Jonet, L.; Savoldelli, M.; Omri, B.; Crisanti, P. Microglia/macrophages migrate through retinal epithelium barrier by a transcellular route in diabetic retinopathy: Role of PKCzeta in the Goto Kakizaki rat model. Am. J. Pathol. 2011, 179, 942. [CrossRef] [PubMed]

33. Allen, R.S.; Feola, A.; Motz, C.T.; Ottensmeyer, A.L.; Chesler, K.C.; Dunn, R.; Thulé, P.M.; Pardue, M.T. Retinal Deficits Precede Cognitive and Motor Deficits in a Rat Model of Type II Diabetes. Investig. Ophthalmol. Vis. Sci. 2019, 60, 123-133. [CrossRef] [PubMed]

34. Weymouth, A.E.; Vingrys, A.J. electroretinography: Methods for extraction and interpretation of rod and cone responses. Prog. Retin. Eye Res. 2007, 27, 1-44. [CrossRef] [PubMed]

35. Pardue, M.T.; Barnes, C.S.; Kim, M.K.; Aung, M.H.; Amarnath, R.; Olson, D.E.; Thulé, P.M. Rodent Hyperglycemia-Induced Inner Retinal Deficits are Mirrored in Human Diabetes. Trans. Vis. Sci. Tech. 2014, 3, 6. [CrossRef]

36. Hancock, H.A.; Kraft, T.W. Oscillatory potential analysis and ERGs of normal and diabetic rats. Investig. Ophthalmol. Vis. Sci. 2004, 45, 1002-1008. [CrossRef]

37. Daruich, A.; Matet, A.; Moulin, A.; Kowalczuk, L.; Nicolas, M.; Sellam, A.; Rothschild, P.R.; Omri, S.; Gélizé, E.; Jonet, L.; et al. Mechanisms of macular edema: Beyond the surface. Prog. Retin. Eye Res. 2018, 63, 20-68. [CrossRef] [PubMed]

38. Yang, Q.; Xu, Y.; Xie, P.; Cheng, H.; Song, Q.; Su, T.; Yuan, S.; Liu, Q. Retinal Neurodegeneration in db/db Mice at the Early Period of Diabetes. J. Ophthalmol. 2015, 757412. [CrossRef]

39. Tanaka, Y.; Takagi, R.; Ohta, T.; Sasase, T.; Kobayashi, M.; Toyoda, F.; Shimmura, M.; Kinoshita, N.; Takano, H.; Kakehashi, A. Pathological Features of Diabetic Retinopathy in Spontaneously Diabetic Torii Fatty Rats. J. Diabetes Res. 2019, 8724818. [CrossRef]

40. Griepp, D.W.; Lee, J.; Moawad, C.M.; Davati, C.; Runnels, J.; Fiani, B. BIIB093 (Intravenous Glibenclamide) for the Prevention of Severe Cerebral Edema. Surg. Neurol. Int. 2021, 12, 80. [CrossRef]

41. Zhao, J.; Yang, F.; Song, C.; Li, L.; Yang, X.; Wang, X.; Yu, L.; Guo, J.; Wang, K.; Fu, F.; et al. Glibenclamide Advantage in Treating Edema After Intracerebral Hemorrhage (GATE-ICH): Study Protocol for a Multicenter Randomized, Controlled, Assessor-Blinded Trial. Front. Neurol. 2021, 12, 656520. [CrossRef] [PubMed]

42. Simard, J.M.; Chen, M.; Tarasov, K.V.; Bhatta, S.; Ivanova, S.; Melnitchenko, L.; Tsymbalyuk, N.; West, G.A.; Gerzanich, V. Newly Expressed SUR1-Regulated NC(Ca-ATP) Channel Mediates Cerebral Edema after Ischemic Stroke. Nat. Med. 2006, 12, 433-440. [CrossRef] [PubMed]

43. Zhang, G.; Lin, X.; Zhang, S.; Xiu, H.; Pan, C.; Cui, W. A Protective Role of Glibenclamide in Inflammation-Associated Injury. Mediat. Inflamm. 2017, 2017, 3578702. [CrossRef]

44. Huang, L.; You, J.; Yao, Y.; Xie, M. High Glucose Induces Pyroptosis of Retinal Microglia through NLPR3 Inflammasome Signaling. Arq. Bras. Oftalmol. 2021, 84, 67-73. [CrossRef] [PubMed]

45. Li, R.; Chen, L.; Yao, G.-M.; Yan, H.-L.; Wang, L. Effects of Quercetin on Diabetic Retinopathy and Its Association with NLRP3 Inflammasome and Autophagy. Int. J. Ophthalmol. 2021, 14, 42-49. [CrossRef]

46. Louie, H.H.; Shome, A.; Kuo, C.Y.; Rupenthal, I.D.; Green, C.R.; Mugisho, O.O. Connexin43 Hemichannel Block Inhibits NLRP3 Inflammasome Activation in a Human Retinal Explant Model of Diabetic Retinopathy. Exp. Eye Res. 2021, 202, 108384. [CrossRef]

47. Rabbani, S.I.; Devi, K.; Khanam, S. Protective role of glibenclamide against nicotinamide-streptozotocin induced nuclear damage in diabetic Wistar rats. J. Pharm. Pharm. 2010, 1, 18-23.

48. Ladrière, L.; Malaisse-Lagae, F.; Fuhlendorff, J.; Malaisse, W.J. Repaglinide, glibenclamide and glimepiride administration to normal and hereditarily diabetic rats. Eur. J. Pharmacol. 1997, 335, 227-234. [CrossRef] [PubMed] 
49. Kitahara, Y.; Miura, K.; Takesue, K.; Mine, T.; Wada, R.; Uchida, Y.; Ito, S.; Yagihashi, S. Decreased blood glucose excursion by nateglinide ameliorated neuropathic changes in Goto-Kakizaki rats, an animal model of non-obese type 2 diabetes. Metabolism 2002, 51, 1452-1457. [CrossRef]

50. Pandarekandy, S.T.; Sreejesh, P.G.; Thampi, B.S.H.; Sreekumaran, E. Hypoglycaemic Effect of Glibenclamide: A Critical Study on the Basis of Creatinine and Lipid Peroxidation Status of Streptozotocin-induced Diabetic Rat. Indian J. Pharm. Sci. 2017, 79. [CrossRef]

51. Blitzer, A.L.; Ham, S.A.; Colby, K.A.; Skondra, D. Association of Metformin Use with Age-Related Macular Degeneration: A Case-Control Study. JAMA Ophthalmol. 2021, 139, 302-309. [CrossRef] [PubMed]

52. Romdhoniyyah, D.F.; Harding, S.P.; Cheyne, C.P.; Beare, N.A.V. Metformin, A Potential Role in Age-Related Macular Degeneration: A Systematic Review and Meta-Analysis. Ophthalmology 2021, 10, 245-260. [CrossRef]

53. Daruich, A.; Jaworski, T.; Henry, H.; Zola, M.; Youale, J.; Parenti, L.; Naud, M.-C.; Delaunay, K.; Bertrand, M.; Berdugo, M.; et al. Oral Ursodeoxycholic Acid Crosses the Blood Retinal Barrier in Patients with Retinal Detachment and Protects Against Retinal Degeneration in an Ex Vivo Model. Neurotherapeutics 2021. [CrossRef] 